\title{
Practices Food Safety amongst Mobile Food Handlers in Shah Alam, Selangor
}

\author{
Faridah Hanim Ismail, Chemah Tamby Chik, \\ Rosmaliza Muhammad, Norhayati Mat Yusoff \\ Faculty of Hotel \& Tourism Management, \\ Universiti Teknologi MARA/Malaysia. \\ farid942@ uitm.edu.my
}

\begin{abstract}
This study seeks to examine the awareness of food handler personal hygiene on food hygiene practices. Using quantitative approach, self-administered questionnaire was distributed to 400 mobile handlers in Shah Alam Selangor,Malaysia and only 320 questionnaires were collated. Although food handlers may be aware of the need for personal hygiene, they do not understand critical aspects of personal hygiene such cleaning work surface and control food temperature value while cooking. In order to prevent food borne illnesses, mobile food owners need to access and improve operator's knowledge, personal hygiene and the hygiene practices on food safety to consumer.
\end{abstract}

Keywords: food safety knowledge; Presonal hygiene; Hygiene Practices; Mobile food handler

eISSN: 2398-4279 @ 2016. The Authors. Published for AMER ABRA by e-International Publishing House, Ltd., UK. This is an open access article under the CC BY-NC-ND license (http://creativecommons.org/licenses/by-ncnd/4.0/). Peer-review under responsibility of AMER (Association of Malaysian Environment-Behaviour Researchers), ABRA (Association of Behavioural Researchers on Asians) and cE-Bs (Centre for EnvironmentBehaviour Studies), Faculty of Architecture, Planning \& Surveying, UniversitiTeknologi MARA, Malaysia. https://doi.org/10.21834/ajqol.v1i4.15 


\subsection{Introduction}

Food essentially functions as a core to fulfill hunger. It is served to fulfilling biological needs as incorporated in the very popular hierarchy pyramid developed by Abraham Maslow (1954). It is supported by Moon (2010) who noted that food consumption is reflected as a simple act of fulfilling biological needs.Conner \& Armitage (2002) generally overviewed food at its lowest level of abstraction is necessary to sustain life. Indeed, foods serve beyond the boundary of gastrointestinal tract and more than just a nutritional fact and value. Furthermore food now can be enjoyed either at home or outside. With the mushrooming of restaurants, street hawkers and other food establishments, people most probably seek the place not only to satisfy hunger but a place to socialize (Lucca, Elizabeth and Torres, 2006). Food consumption activities have changed due to the influence of people's life-style (Muinde and Kuria, 2005; Omemu and Aderoju, 2008; Choudhury, Mahanta, Goswami, Mazumder and Pegoo, 2010; Abdalla, Suliman and Bakhiet, 2009). For instance, less food preparation at home and escalation in number of meals eaten out of home (Osaili,Obediat, Abu Jamous and Bawadi, 2011).However, the increased numbers of people eating out have caused the emergence of food borne illness due to unhygienic preparation and lack of knowledge of personal hygiene (Ghazali ,Othman, Nashuki and Roslan, 2012).

Whereby food is prepared or sold at public places and can be taken-way or eaten near the mobile place (Abdalla, Sulaiman and Bakhiet, 2009). Mobile food handlers' are responsible in providing safe food for the intake of their customers (Martins, Hogg, and Otero, 2012).A studies conducted by Food Agriculture Organization (1995) recorded that poor knowledge lead to poor practices in food handling base on the assessment of microbial contamination of food sold by the mobile food handlers. Improper food preparation practices can cause food borne illness as contended by Park, Kwak and Chang (2010). According to Omemu, and Bankole (2005), when food handlers do not practice proper food safety, personal hygiene during food preparation, they may become vehicles for microorganism's for example through their hand, mouth and skin.

Mobile food handlers' are responsible in providing safe food for the intake of their customers (Martins, Hogg, and Otero, 2012). As a product that is rich in nutrients required by microorganisms, the growth of bacteria in food may be showing to contamination through the major sources like water, air, dust, equipment, sewage, insects, rodents and food handler (Nee and Sani, 2011). As a result of changes in food preparation techniques as well eating habits, these will increase the chances of food contamination due to improper food handling.

\subsection{Literature Review}

There are many sites that mobile food vendors and temporary stalls operate (Muyanja, Nayiga, Brenda and Nasinyama, 2011). Commonly there are available at busy street-sides and corners as well as bus stands (Muyanja et al., 2011). As in most emerging countries, 
poor food hygiene and food handling practices were among the most alarming problems faced by the food control authority (Selamat and Hassan, 2003). The safety of mobile food handler is affected by several influence starting from the quality of the raw material, to food handling and storage practices. In most cases, the process of preparing street food is exposed to unpleasant environmental condition compared to food that prepared in premises.These practices had been seen among mobile food handlers and hawkers as well as the numerous small-scale food processors or cottage industries throughout the country (Muyanja et al., 2011).

Therefore, this study was seek to examine the influence of food safety knowledge amongst mobile food handlers with hygiene practices and to investigate to what extent does mobile food handlers' personal hygiene influence their hygiene practices .(Saidatul AfazanAbdulAziz \& Hayati Mohd Dahan 2013)

\subsection{Methodology}

It has been reported that the number of cases in Malaysia for the first month of 2008 showed that it is an alarming increase with 257 cases of food poisoning were reported as compare to only 34 cases for the same stage in 2007 (Ministry of Health, 2008). Food handlers that fail to perform the basic rule of food preparation such as mistreatment of the food and lack can hygiene practice contributed to of food poisoning ( M. O. Rashidi, Zuraini M.I and K. Mohammad Nor, 2009). Therefore Food safety a principal consideration in administering the food chain and an essential aspect in protecting the nation's health (kinight, 2007). Research on foodborne illness risk factors indicates that most outbreaks in food service establishments can be attributed to food workers' improper food preparation practices (Bryan, 1988).

Food safety the WHO has mentioned the popularity of street food stalls as a contributory factor to food-borne illness globally (WHO, 2002). There are researcher indicated that poor hygiene and food safety practices (FSPs) many food hawkers in Malaysia lead to this problem while (Zain,2002 Toh and Birchenough, 2000; Toh et al, 2000) indicated that food safety knowledge, attitude and sociodemographic factors, educational level and ethnicity of hawkers or mobile food handlers can influnce of their knowledge in food safety practices.Nowdays,food safety is a vital issue that has to be taken into consideration when talk about public health (Mohd Shahid \& Winsson, 2012).

In Malaysia, lack of food safety awareness might be a significant contributor to the increase numbers of food borne illnesses (Nee \& Sani, 2011). Apart from that there are few factors and in order to change behavior health that the programmers need to address in order to change consumers' behavior economic including socio-cultural, environmental, economic and structural factors (Launiala, 2009). However knowledge, and it was found to play a vital role in the cognitive processing of information in the attitude-behavior 
relationship (Simelane,2005) beside, it has traditionally been assumed that knowledge is automatically translated into behavior (Glanz , \& Lewis, 2002 )

The mobile food handlers' plays an important role to make that the food that they sell is safe for consumer to eat. (Abdalla et al.,2009). Particular attention should be given on the role of mobile food handlers in prevention of contamination and temperature abuse of food. Drinking and smoking are strictly prohibited in any food preparation or foodservice area. Any person with open cuts, sores, or wounds is strictly prohibited from food preparation and or service (Bas et al., 2006).

Mobile food handlers need to ensure appropriate cleanup and sanitation of all affected areas and equipment and also discard any contaminated or potentially contaminated food. Hand washing booths without hot and cold running water shall provide a minimum two gallon container of water with a spigot to provide gravity flow, liquid soap, and paper towels for hand wash, along with a water-tight catch basin for grey water generated at the hand wash station (Askarian et al.,2004; Angelilio et al . 2001).

\subsection{Results And Discussions}

This research was carried out using a five sections Likert scale questionnaire adopted from previous researches in 2010 as the main instrument and will base on the research questions arising from the literature review. The study was carried out from April to May 2013 the questionnaire took approximately 20 minutes to be complete to answer and used self-administered .

A total of 400 questionnaires were distributed to food handlers before or after they operated for business. Questions On demographics and personal hygiene were incorporated for research opportunity to further information knowledge or contrast and also to compare with other studies in the field. The sample for this study involved the total numbers of food handlers in Shah Alam. Geographic area samplings (cluster sampling) were used based on districts in Shah Alam, Selangor.

\subsection{Respondents' Profile}

Based on table 1 it shows that most $28 \%$ of respondents were between 32 to 38 years old. $27.5 \%$ of respondent aged between 25 to 31 years old. While ages between 39 to 45 years old $24.1 \%$. The age between 46 and above $7.8 \%$ is lowest group of people

Table 1: Age group

\begin{tabular}{ccc}
\hline Gender & Frequency $(\mathrm{n}=320)$ & Percentage \\
\hline Male & 168 & 52.5 \\
Female & 150 & 46.9 \\
\hline
\end{tabular}




\section{2 Race}

Table 2 shows that the most $(67.2 \%)$ of the respondent were Malay followed by Chinese (7.5\%) Indian (9.7\%) and others races is Indonesian ethnics (15.6\%)

Table 2: Race

\begin{tabular}{ccc}
\hline Race & Frequency $(\mathrm{n}=320)$ & Percentage \\
\hline Malay & 215 & 67.2 \\
Chinese & 24 & 7.5 \\
Indian & 31 & 9.7 \\
Others & 50 & 15.6 \\
\hline
\end{tabular}

\subsection{Highest Education Background}

Table 3 shows the highest level of attained by the respondents. Most $(42.2 \%)$ had of them SPM/MCE/STPM qualification followed by Degree holder (3.1\%) Diploma holder (15.3\%) SRP/LCE/PMR qualification (5.6\%) and Primary school qualification (20\%) certificate qualification (13.8\%)

Table 3: Education

\begin{tabular}{|c|c|c|}
\hline Education & Frequency(n=320) & Percentage \\
\hline Primary school & 64 & 20.0 \\
\hline PMR/LCE/SRP & 18 & 5.6 \\
\hline SPM/MCE/STPM & 135 & 42.2 \\
\hline Diploma & 49 & 15.3 \\
\hline Degree & 10 & 3.1 \\
\hline Certificate & 44 & 13.8 \\
\hline
\end{tabular}

\subsection{Income}

Table 4 : Income group

Income

Less thanRM1000

RM1000 to RM2000

RM2001 to RM3000

RM3001 to RM4000

RM4001 to RM5000

$\begin{array}{cc}21 & 6.6 \\ 139 & 43.4 \\ 128 & 40.0 \\ 24 & 7.5 \\ 8 & 2.5\end{array}$


Table 4 show the respondent income based on four categories of respondents earned between RM 1000 to 2000 (43.4\%) per month follow by RM 2001 toRM3000 (40\%) RM 30001 - RM 4000 and $2.5 \%$ earned in categories RM4000 to RM 5000.

\subsection{Marital Status}

Looking at the table 5 for the marital status respondents $65.6 \%$ single, $30 \%$ married, $41.1 \%$ single parent and. $3 \%$ Widower

Table 5: Marital Status

\begin{tabular}{cc}
\hline Marital Status & Percentage \\
\hline Single & 65.6 \\
Married & 30.0 \\
Single parent / Separated & 4.1 \\
\hline
\end{tabular}

\subsection{Involved Year}

Based table on table. 6 the number years of respondents involvement in mobile food business are reported $49.7 \%(n=159)$. There is business less than 1 year of involvement $28.1 \%$ and 5 to 7 years of involvement $15.6 \%$. The involvement year 8 to 10 is only $5.0 \%$. , The 11 years and above involvement $1.6 \%$.

Table 6: Involvement in mobile business

\begin{tabular}{lcc}
\hline Involvement year & Frequency & Per cent \\
\hline & 90 & \\
Less than 1 year & 159 & 28.1 \\
2 to 4 years & 50 & 49.7 \\
5 to 7 years & 16 & 15.6 \\
8 to 10 years & 5 & 5.0 \\
11 years and above & & 1.6 \\
\hline
\end{tabular}

\subsection{Personal Hygiene}

Based on table 7, the personal hygiene items of the mobile food handlers showed ( $M=4.59$, $S D=0.790)$ the statements they washed their hand after smoking $(M=4.09, S D=1.051)$ and used a clean towel to wipe their hand $(M=4.08, S D=0.809)$. Thus, it can be concluded that the respondent knew the personal hygiene. The respondents washed their hand after handling the garbage $(M=4.59, S D=0,780)$.After blowing nose they washed their hand $(M$ $=4.48, S D=0.885)$. They know that Diarrhoea can cause food poisoning $(M=4.26$, SD 
$=1.050$ ), the respondent will make sure they will cough during of food preparation( $M=4.42$ ,$S D$ 2.68), After the cleaning table they washed their hand $(M=4.45, S D=0.825$ They are sick during handling the food $(M=4.35, S D=0.908)$.

Table 7: Mean score For Personal Hygiene

Variables

Mean (M)

\begin{tabular}{l}
\hline I wash my hand after handling money \\
I wash my hand after meal \\
I wear gloves before touching the ready-to-eat food product \\
I wash my hand after cleaning table \\
I wash my hand before preparing meals \\
I wash my hand after handling the garbage \\
I wash my hand after blowing my nose \\
I make sure my nails are cut short \\
I wear hairnet when work in food service \\
I am smoking during food served \\
I wash my hand after smoking \\
I used clean apron while serve the food \\
I wear clean uniform during preparation of food \\
I use clean towel to wipe my hand \\
Diarrhoea would cause food poisoning \\
I will make sure I am not cough during preparation of food \\
I used mouth cover during food handling \\
I will make sure I am not sick during food handling \\
I also wash my hand after touching other food
\end{tabular}

$\begin{array}{cc}3.19 & 1.416 \\ 4.50 & .850 \\ 3.14 & 1.524 \\ 4.45 & .825 \\ 4.59 & .790 \\ 4.59 & .780 \\ 4.48 & .885 \\ 2.99 & 1.247 \\ 2.99 & 1.247 \\ 2.37 & 1.282 \\ 4.09 & 1.051 \\ 3.82 & .779 \\ 3.78 & .774 \\ 4.08 & .809 \\ 4.26 & 1.050 \\ 4.42 & 2.68 \\ 2.68 & 1.417 \\ 4.35 & .908 \\ 4.31 & .951\end{array}$

\subsection{Food Hygiene Practice}

The mean scorer for each item measuring are listed in the dependent variable, food hygiene practice. Respondents strongly agree food need to be keep in the fridge for two hours before cooking $(M=4.09, S D$ 0.955) and cook food need to be cover while preparing and selling the food $(M=4.22, S D=0.955),(M=4.24, S D=0.938)$. The food were serve using a food thongs, fork and spoon with should be put in a clean tray and with cover $(M=$ $4.2, S D=0.938$ )

Table 8 Mean score Food Hygiene Practice

\begin{tabular}{|l|c|c|}
\hline Variables & Mean (M) & $\begin{array}{c}\text { Std Deviation } \\
\text { (SD) }\end{array}$ \\
\hline I cook and sell food at the same time & 3.89 & 1.269 \\
\hline I cook food 2 hours before my business activity & 3.18 & 1.451 \\
\hline I always serve food in a tray with cover & 4.22 & .890 \\
\hline
\end{tabular}


Ismail, F.H., et.al., / Asian Journal of Quality of Life, AjQoL, 1(4), Nov. / Dec. 2016 (p.31-40)

\begin{tabular}{|l|c|c|}
\hline I serve food in a clean tray & 4.24 & .955 \\
\hline $\begin{array}{l}\text { I will keep the food in fridge for two hours before preparing } \\
\text { and sell }\end{array}$ & 4.09 & .955 \\
\hline $\begin{array}{l}\text { I will practices safety method to store food before preparing } \\
\text { and sell }\end{array}$ & 4.29 & .921 \\
\hline I used plate which is covered with plastic to serve the food & 2.87 & 1.319 \\
\hline I will always practice using new glove when serve food & 2.71 & 1.306 \\
\hline I serve food with glove & 3.17 & 1.192 \\
\hline I served food with fork ,spoon and food thongs & 4.24 & .938 \\
\hline
\end{tabular}

(Scale, 1= Strongly, Disagree, 2=Disagree,3= Neither Agree / Nor Disagree , 4 = Agree 5 = Strongly Agree)

\subsection{Result Of Liner Regression}

Based on the table 9 , the highest standardized beta coefficient was food safety knowledge $(\beta=0.624, P=0.000)$ determine as a largest influence and makes the strongest contribution to explain on food safety knowledge toward food hygiene practices. For the personal hygiene, the standard beta coefficient $(\beta=0.478, p<0.001)$ was the second highest which showed that moderate contribution towards food hygiene practices. Meanwhile, the beta value for cross contamination $(\beta 0.236, p<0.001)$ was low which showed that it made less contribution to food hygiene practices. In conclusion, food safety knowledge was considered as the most influential factors in predicting food hygiene practices and both predictors made statistically significant contributions to food hygiene practices.

Table 9 Result of Liner Regression

\begin{tabular}{llll}
\hline Variable & B & Std Error & Beta \\
\hline Food Safety Knowledge & .795 & 0.56 & .624 \\
Cross Contamination & .565 & .060 & .236 \\
Personal Hygiene & .502 & .053 & .478 \\
\hline
\end{tabular}

Dependent Variable: Food hygiene Practices $\mathrm{R}^{2}=.63 .2 \%{ }^{*}, \mathrm{p}<0.001$

Although food safety studies have been conducted for a long time, the results showed that food safety knowledge had one common understanding regarding food safety knowledge content (Griffith \& Boatright, 2003). However, the mobile food handlers that have knowledge on food safety did not always put it into food hygiene practices (Oteri \& Ekanem 1998). In this study, the regression analysis showed that food safety knowledge is the strongest predictor of food hygiene practices. The highest standardized beta coefficient indicated that $(\beta=0.624, p<0.05)$. Perhaps, still many mobile food handlers in Shah Alam, Selangor who did not realized the important of food safety. The main reason of this was food handlers who involved in mobile food, stall, hawkers activities were not all registered with local government, mobile food handlers had low level of education and were not trained (Zain \& Naing , 2002) 
This study suggested there is positive relationship between food safety knowledge personal hygiene and food hygiene practices among mobile food handlers. The result indicated that the food safety knowledge was significantly correlated to personal hygiene. In order to decrease the risk of cross contamination, training which is being incorporated into the existing principles or other related guideline for the mobile food handlers. In addition, the study also helps consumer to be aware that the quality of food and safe food to the consumer.

\subsection{Conclusion}

Even though mobile food handlers are aware of the need for personal hygiene, more awareness needs to be created. Mobile food handlers need to be kept neat always, refuse or waste should be disposed as soon as possible while rodents, cats and insects areas stopped from getting into the dining area in the restaurants or where food is being prepared so as not to contaminate raw food materials. Continuous on the job training on personal hygiene is recommended for mobile food handlers. In addition, mobile food handlers should be given more awareness on food safety and hygiene practices and personal hygiene to prevent outbreak and spread of food -borne diseases to customer but also ready to eat foods.

\section{References}

Maslow, A. (1954). Motivation and personality. New York, NY: Harper.

Griffith\& Boatright,(2003).A Comparison of Food Safety International Journal of Environmental Health Research, 12. 25-39. 9.

M.A.Abdalla, S. E. S. and A. . B. (15AD). food safety knowledge and practices of mobile food vendor in Atbara city( naher elneel state student). http;//www.academicjurnals.org/AJB, 8(24), 696-6971.

Muyanja, C., Nayiga, L., Brenda, N., \& Nasinyama, G. (2011). Practices, knowledge and risk factors of street food vendors in Uganda. Food Control, 22(10), 1551-1558. doi:10.1016/j.foodcont.2011.01.016

Park, S.-H., Kwak, T.-K., \& Chang, H.-J. (2010). Evaluation of the food safety training for food handlers in restaurant operations. Nutrition research and practice, 4(1), 58-68. doi:10.4162/nrp.2010.4.1.58

Osaili, T. M., Abu Jamous, D. O., Obeidat, B. a., Bawadi, H. a., Tayyem, R. F., \& Subih, H. S. (2013). Food safety knowledge among food workers in restaurants in Jordan. Food Control, 31(1), 145-150. doi:10.1016/j.foodcont.2012.09.037

Zain, M. M., Naing, N. N., \& Sains, U. (2002).Southeast Asian J T Rop Med Public Healthsociodemographic Charactristic of food handlers and Their knowledge, attitude and Practices toward Food Sanitation. 
Ismail, F.H., et.al., / Asian Journal of Quality of Life, AjQoL, 1(4), Nov. / Dec. 2016 (p.31-40)

Mohd Shahid N.S. \& Whisson. J. (2012). Effectiveness of the Tees Valley Food Hygiene Award Scheme towards Food Business Operators and Consumers in the Middleborough District. Procedia - Social and Behavioral Sciences.49, 368-380. 